3 Wood AM, Simmonds MJ, Bayley DL, et al. The TNFalpha gene relates to clinical phenotype in alpha-1-antitrypsin deficiency. Respir Res 2008; 9: 52.

4 Genetic information from the 1958 Birth cohort 2009. www. b58cgene.sgul.ac.uk Date last assessed: August 20, 2009.
5 Demeo DL, Campbell EJ, Barker AF, et al. IL10 polymorphisms are associated with airflow obstruction in severe alpha1-antitrypsin deficiency. Am J Respir Cell Mol Biol 2008; 38: 114-120.

DOI: 10.1183/09031936.00134709

\title{
Equipment for multiple breath washout
}

\section{To the Editors:}

We read with interest the article "Paediatrics in Berlin" [1] in a recent issue of the European Respiratory Journal, which summarised the paediatric topics of the European Respiratory Society's Annual Congress in Berlin.

In this article, inert gas multiple breath washout (MBW) technique was highlighted as a promising tool for assessing parameters of ventilation inhomogeneity, such as the lung clearance index (LCI) for detecting early peripheral airway disease, e.g. in cystic fibrosis. However, equipment using mass spectrometry, the current "gold standard" for MBW, has no prospect to become commercially available. Alternatively, an ultrasonic flow sensor or an infrared analyser has been introduced for indirectly measuring gas concentrations during a washout procedure. Our recent study reporting within-test repeatability and between-test reproducibility of the LCI in healthy children and adolescents using a side-stream ultrasonic flow sensor [2] was cited in this article [1].

As there has already been a lot of confusion regarding equipment for MBW, we feel it is important to emphasise that we did not use equipment sold by Eco Medics (Dürnten, Switzerland) for any of our studies in preschool children through to adults.

Rather, we have developed equipment based on a similar flow sensor but with the sensor in a side-stream position, utilising a sophisticated valve system controlled by the appropriate software. This equipment is not yet commercially available but was developed as EasyOne Pro, MBW module, in collaboration with ndd Medical Technologies (Zurich, Switzerland). This prototype equipment has been validated in a stepwise approach including comparison with the gold standard mass spectrometry [3], proof of hygienic safety [4], demonstration of feasibility in patients with cystic fibrosis and healthy controls [5], data on short-term and long-term variability in healthy subjects [6] and will now be used in a multicentre trial.

\section{S.I. Fuchs*,\# and M. Gappa ${ }^{\#}$}

*Paediatric Pulmonology and Neonatology, Hannover Medical School, Hannover, and "Children's Hospital and Research Institute, Marien Hospital Wesel, Wesel, Germany.

Correspondence: S.I. Fuchs, Paediatric Pulmonology and Neonatology, Hannover Medical School, Carl-Neuberg-Str.1, 30625 Groß-Buchholz, Hannover, Germany. E-mail: fuchs.susanne@mh-hannover.de
Statement of Interest: A statement of interest for M. Gappa can be found at www.erj.ersjournals.com/misc/statements.dtl

\section{REFERENCES}

1 Barbato A, Bertuola F, Kuehni C, et al. Paediatrics in Berlin. Eur Respir J 2009; 34: 436-443.

2 Fuchs SI, Gappa M. Multiple breath washout (MBW): within-test repeatability and short-term reproducibility of FRC and lung clearance index (LCI) in healthy children and adolescents. Eur Respir J 2008; 32: Suppl. 52, 300s.

3 Fuchs SI, Buess C, Lum S, et al. Multiple breath washout with a sidestream ultrasonic flow sensor and mass spectrometry: a comparative study. Pediatr Pulmonol 2006; 41: 1218-1225.

4 Fuchs SI, Gappa M, Waltner-Romen M, et al. Hygienic safety of an ultrasonic flow sensor for multiple breath washout. Pediatr Pulmonol 2009; 44: 99-100.

5 Fuchs SI, Sturz J, Junge S, et al. A novel sidestream ultrasonic flow sensor for multiple breath washout in children. Pediatr Pulmonol 2008; 43: 731-738.

6 Fuchs SI, Eder J, Ellemunter $\mathrm{H}$, et al. Lung Clearance Index: normal values, repeatability and reproducibility in healthy children and adolescents. Pediatr Pulmonol 2009; 44: 1180-1185.

DOI: $10.1183 / 09031936.00159509$

\section{From the authors:}

We thank S.I. Fuchs and M. Gappa for their interest in our review [1]. The points they make are of general importance. As with all lung function measurements, lung clearance index (LCI) must be measured with equipment that has adequate frequency responses, precision and stability, and has been suitably calibrated. Their work with an ultrasonic flow meter is welcome, because it has been compared with a gold standard, and may make measurement of LCI more accessible. The use of equipment which has not been so carefully validated must be firmly discouraged.

\section{A. Bush* and P. Seddon ${ }^{\#}$}

* Royal Brompton Hospital and Imperial College, London, and

"Royal Alexandria Hospital, Brighton, UK. 